\title{
Język - kultura - człowiek \\ Wokół książki Lingwistyka kulturowa i międzykulturowa. Antologia pod redakcją Waldemara Czachura (Warszawa 2017, 338 s.)
}

\author{
Language - Culture - Man. About the Book \\ Lingwistyka kulturowa i międzykulturowa. Antologia \\ edited by Waldemar Czachur (Warszawa 2017, 338 pp.)
}

Relacje pomiędzy językiem (komunikacją) i kulturą zajmowały badaczy od dawna. W językoznawstwie wyodrębniły się subdyscypliny mające za przedmiot kulturowe uwikłania języka, przyjmując nazwy lingwistyki kulturowej, etnolingwistyki czy językoznawstwa antropologicznego - by wymienić tylko te funkcjonujące na gruncie polskim. W naszym środowisku naukowym zainteresowanie wielowymiarowymi powiązaniami języka i kultury znalazło wyraz $w$ przedsięwzięciach o charakterze instytucjonalnym - czasopismach naukowych: wrocławskim roczniku „Język a Kultura” i lubelskiej „Etnolingwistyce” (również wydawanej raz $w$ roku).

Badacze zainteresowani uwarunkowaniami kulturowymi komunikacji kierują dziś uwagę także na zjawisko międzykulturowości i komunikacji międzykulturowej. Jak pisze Ryszard Kapuściński:

Nasza planeta zawsze była co prawda wielokulturowa, od niepamiętnych czasów ludzie mówili na niej różnymi językami i wierzyli $w$ różnych bogów, ale tak potoczyły się losy świata, że przez ostatnie pięć wieków dominowała nad nami kultura czy cywilizacja europejska [...].

KAPUŚCIŃSKI, 2007: 57

Dopiero jednak przemiany polityczne, gospodarcze i ekonomiczne XXI wieku sprawiły, że wielokulturowości doświadczamy niemal codziennie, a inność jest na wyciągnięcie ręki. Spotkanie/zderzenie się odmiennych kulturowo społeczności może być, jak przekonywał Kapuściński, wzbogacające, rodzi jednak również nieporozumienia czy konflikty. Dlatego rozwijające się $w$ dobie globalizacji studia międzykulturowe przynoszą korzyści nie tylko poznawcze, ale i praktyczne.

Tym dwóm zagadnieniom - relacjom języka i kultury oraz międzykulturowości - została poświęcona antologia pod redakcją Waldemara Czachura. Książka gromadzi teksty

\footnotetext{
* e-mail: b.ciesek@wp.pl

1 Tekst pierwotnie wygłoszony 30 września 2003 roku w Krakowie jako wykład inaugurujący rok akademicki w Wyższej Szkole Europejskiej im. ks. Józefa Tischnera.
} 
zachodnich badaczy, głównie germanistów oraz naukowców związanych z anglojęzycznymi ośrodkami naukowymi, co stanowi niewątpliwą zaletę publikacji: przybliża ona polskim humanistom stanowiska naukowców i ich osiągnięcia na gruncie innych tradycji badawczych. Autorzy pomieszczonych w zbiorze prac omawiają najbardziej doniosłe teoretyczne ujęcia z zakresu lingwistyki kulturowej i międzykulturowej, a także prezentują własne projekty badawcze i wskazują możliwe kierunki rozwoju tych subdyscyplin.

Tom otwiera artykuł redaktora, Waldemara Czachura (Lingwistyka kulturowa i międzykulturowa. Pytania badawcze, zadania i perspektywy), stanowiący wprowadzenie do kolejnych ośmiu tekstów poruszających wybrane problemy w obrębie tytułowej tematyki. Autor prezentuje stan badań $w$ dziedzinie lingwistyki kulturowej i międzykulturowej, szczególnie skupiając się na celach poznawczych badaczy. W dalszej kolejności zarysowuje konteksty powstania lingwistyki kulturowej w polskiej i niemieckiej nauce, a obiektem porównania stają się: przedmiot badań, cele i zakres zadań subdyscypliny. Śledząc etapy konstytuowania się lingwistyki kulturowej, Czachur rozpoczyna od zwrotu językowego, którego efektem jest zainteresowanie relacją język - kultura, oraz przypomina kolejne zwroty ujmujące relacje pomiędzy językiem a rzeczywistością pozajęzykową oraz najważniejsze opracowania powstałe $w$ tym duchu. Różnice $w$ polskich i niemieckich badaniach, jak pisze autor, nastąpiły $w$ kolejnym etapie rozwoju, kiedy to zainteresowanie zdarzeniowością zjawisk językowych doprowadziło w kręgu polskim do powstania prac teoriotekstowych, a także dotyczących kwestii nadawczo-odbiorczych i uwarunkowań zewnętrznych. Lingwiści niemieccy pozostali natomiast pod wpływem szkół strukturalistycznych. Tu aspekty społeczne i kulturowe języka pojawiły się z uwagi na rozwój lingwistyki dyskursu. Dziś, ze względu na uwarunkowania społeczne i gospodarcze, w Niemczech obserwujemy zaawansowane badania nad komunikacją międzykulturową. Kończąc opis ewolucji lingwistyki kulturowej na omówieniu wpływów neohumboltyzmu, amerykańskiego kognitywizmu, rosyjskiej semantyki i semiotyki, badacz dokonuje przeglądu wybranych koncepcji tej subdyscypliny. Ostatnią część swej pracy poświęca wskazaniu zadań lingwistyki międzykulturowej i przedmiotu jej badań oraz opisowi paradygmatu badawczego.

Drugi $w$ antologii tekst, autorstwa Susanne Tienken (Wzorce językowe a analiza kulturowa. Ujęcie teoretyczne i metodyczne), dotyczy rozważań nad tym, w jakim stopniu wzorce użyć języka można uznać za kulturowe nadawanie formom sensu, które pozwala usytuować człowieka w świecie i społeczności. Tłem teoretycznym są założenia konstruktywizmu uzupełnione o interakcyjną teorię języka i semiotyczne rozumienie kultury. Posługując się $w$ analizie kulturowej wskazanym $w$ tytule pojęciem znaczących wzorców, autorka nawiązuje do założeń Angeliki Linke na temat teorii komunikacji i traktuje wzorce jako miejsce splotu kultury i języka. Przechodząc do koncepcji metodycznych, wskazuje na cel lingwistyki kulturowej, rozumianej za LıNKE (2011: 40) jako „zwrócenie uwagi przez analizę użycia języka na zjawiska i przeobrażenia kulturowe, które nie leżą jak na dłoni" (s. 47). Tienken wymienia i omawia również metody analizy kulturowej umożliwiające przyjęcie tak ważnej perspektywy obserwatora, nie zaś uczestnika: metodę serialności i zasadę kontrastywności, których kolejnym etapem jest interpretacja nazwana przez badaczkę perspektywicznością. W ostatniej części artykułu autorka opisuje powstawanie wzorców na płaszczyźnie morfologicznej, wzorców komunikacyjnych i gatunków mowy, prezentując jednocześnie metody i cele poznawcze lingwistyki kulturowej. 
Andreas Musolff $w$ tekście Analiza scenariuszy metaforycznych $w$ ramach lingwistyki kulturowej referuje badania nad różnicami znaczeniowymi metafor we wspólnotach odmiennych kulturowo oraz najnowsze ustalenia empiryczne dotyczące recepcji i interpretacji w poznaniu kulturowym. Autor przybliża czytelnikowi między innymi książkę Zoltána Kövecsesa Metaphor in Culture: Universality and Variation (Kövecses, 2005), najnowsze badania nad metaforyzacją emocji $w$ języku angielskim, rosyjskim i hiszpańskim oparte na korpusach (Ogarkova, Soriano, 2014) czy studia diachroniczne (GeEraerts, Grondelaers, 1995). Przytacza także wyniki badań dowodzące, że wyrażenia metaforyczne są różnie rozumiane przez użytkowników drugiego języka - z uwagi na możliwy wpływ kultury języka ojczystego. Takie zmiany $w$ rozumieniu znaczenia mogą prowadzić do niepowodzeń komunikacyjnych, ale i do tworzenia nowych znaczeń. Drugą część artykułu poświęca badacz na zreferowanie wyników pilotażowego sondażu analizującego różnice semantyczne $w$ interpretowaniu metafory NARÓD JAKO CIAŁO wśród respondentów reprezentujących 31 różnych kulturowo i językowo środowisk. Analiza sondaży prowadzi do podania w wątpliwość hipotezy na temat automatycznego rozumienia metafor, będącej podstawą teorii metafory konceptualnej, i wysnucia wniosku o zmienności i uwarunkowaniu kulturowym rozumienia metafor. Autor proponuje również zaadaptowanie koncepcji scenariusza jako podkategorii ram interpretacyjnych do badania języka przenośnego w celu uchwycenia kulturowych aspektów tworzenia recepcji metafor.

W artykule Kulturowe modele autoprezentacji. Wyobrażenia społeczne a stereotypizacja Ruth Amossy, po wstępnych uwagach na temat budowania autoprezentacji w kontekście społecznym, pokazuje, jak utrwalone wyobrażenia zbiorowe (stereotypy) kształtują ethos indywidualny i dodają mu wagi w skonwencjonalizowanych gatunkach dyskursywnych, $w$ których role są na stałe przypisane (np. w pisemnych reklamacjach czy debatach telewizyjnych). Kolejną grupę analizowanych gatunków stanowią te, w których wymagana jest wyjątkowość, na przykład autobiografie gwiazd hollywoodzkich. Stereotypizacja buduje w nich wrażenie autentyczności osoby, prócz tego włącza ją do jednej z kategorii kreowanych przez przemysł filmowy, do której przynależności się wymaga. Jak przekonuje autorka, stereotypizacja występuje także $w$ tych gatunkach, w których niemożliwe okazuje się nawiązanie do istniejących już wzorców. Przykładem ilustrującym tę sytuację jest przemówienie kandydatki na prezydenta Francji, która implicytnie negocjuje ethos - musi wziąć pod uwagę oczekiwania odbiorców, dlatego też aktywizuje męski stereotyp władzy wypełniany przez takie cechy, jak energiczność i zdecydowanie. Model ten kandydatka wzbogaca wizerunkiem matki, dzięki któremu może odróżnić się od swojego konkurenta. Budowanie wizerunku kobiety prezydenta przez odwołanie się do innych stereotypów kompensuje brak modelu. Badaczka opisuje także sytuację mylnego przypisania tożsamości, która występuje, gdy mamy do czynienia z rozbieżnością między założonym stereotypem a jego interpretacją. Niewątpliwie jednak, jak konkluduje Amossy, stereotypizacja etosu służy między innymi zdobywaniu władzy i dominacji.

Drugą część tomu, poświęconą pracom z obszaru lingwistyki międzykulturowej, otwiera Csaba Földes artykułem Czarna skrzynka „Międzykulturowość”. O niewiadomej wiadomej (nie tylko) dla niemieckiego jako języka obcego / języka drugiego. Autor dokonuje opatrzonego krytycznym komentarzem przeglądu rozumienia pojęcia kultury oraz przywołuje modele kultury, które funkcjonują w literaturze fachowej. Następnie koncentruje się na 
międzykulturowości występującej, jak pisze, w kontekście pojęcia kultury, referując badania zachodnie dotyczące tego zjawiska. Badacz wskazuje przy tym kwestie problematyczne we wstępnych badaniach nad kulturą i międzykulturowością, związane na przykład z brakiem wyraźnej granicy między pojęciami kultury i cywilizacji, z niepełną, nieprecyzyjną bądź błędną interpretacją pojęcia międzykulturowości czy też z jego ideologiczno-politycznym nacechowaniem. Wobec tych niedociągnięć Földes proponuje własną koncepcję, zgodnie z którą postuluje badanie międzykulturowości na poziomie obiektu i na poziomie meta-. Co istotne, przyjmuje perspektywę ukierunkowaną na działanie/procesualność. Pozwala ona widzieć międzykulturowość jako proces negocjowania, a więc jako zjawisko dynamiczne, uzależnione od kontekstu. Właśnie $w$ takich tendencjach, akcentujących dynamiczność międzykulturowości, badacz dostrzega największy potencjał, ponieważ odchodzą one od skupiania się na różnicach między produktami kultury, ale interesują się tym, co powstaje w wyniku kontaktowania się kultur. Postuluje także, by badania nad przykładowo wielojęzycznością, konfliktem języków i kultur obejmowały aspekt językoznawczy oraz psycho-, socjo- i pragmajęzykowy.

Do teoretycznych założeń „czarnej skrzynki” Földesa nawiązują Gerd Antos i Anna Lewandowska $w$ artykule $O$ metodach lingwistycznego ujęcia międzykulturowości. Autorzy uzupełniają teorię Földesa o rozwiązania metodyczne, które umożliwiają operacjonalizację „czarnej skrzynki”. Proponują zastosować następujące kroki w procesie analizy języka i komunikacji: po pierwsze, rozpatrując międzykulturowość na płaszczyźnie obiektów, należy zestawić przedmiot badań z odpowiednimi reprezentacjami językowymi z innej kultury, by sprawdzić, czy w ogóle podlegają one porównaniom; po drugie, trzeba sprawdzić, czy zestawione zjawiska charakteryzuje ekwiwalencja; po trzecie, konieczna jest odpowiedź na pytanie, co powinno się brać pod uwagę $w$ rozważaniach nad międzykulturowością na płaszczyźnie meta-. Badacze podkreślają także, że porównań międzykulturowych nie należy redukować do analiz o charakterze konfrontatywnym i kontrastywnym, lecz skupić się na oglądzie strukturalnych podobieństw i różnic relewantnych kulturowo opozycji.

Opracowanie Susanne Günthner Doing Culture - kulturowa samoidentyfikacja i identyfikacja innych $w$ rozmowie ma charakter analityczny. Badaczka przedstawia przykładowe analizy fragmentów rozmów ilustrujące dokonywanie samoidentyfikacji przez interlokutorów oraz identyfikacji innych. Szczególnie interesuje autorkę sposób, w jaki uczestnicy rozmowy tworzą przynależności i odrębności kulturowe, także $w$ kontaktach z użytkownikami tego samego języka. Günthner również, jak i inni badacze międzykulturowości, zakłada, że komunikacja międzykulturowa to proces dynamiczny, zbliżający bądź oddalający komunikujące się kultury. Z kolei założenie o społecznym konstruowaniu zjawisk pozwala wprowadzić termin doing culture. Umożliwia ono przyjrzenie się konstruowaniu przynależności i odrębności kulturowej w codziennej komunikacji. Tak wyznaczone zadanie rodzi potrzebę koncentracji na analizie kontekstu i praktyk dyskursywnych. Analizując na podstawie metod socjolingwistyki interakcyjnej i analizy konwersacyjnej rozmowy osób pochodzenia chińskiego i niemieckiego, pokazuje zjawisko doing culture - nadawanie znaczenia odrębności lub przynależności kulturowej. Kończąc swe rozważania, autorka podkreśla, iż w dobie globalizacji konstruowanie zbieżności i odrębności występuje w różnorodnych kontekstach, w związku z tym badania doing culture powinny wychodzić poza stałe, tradycyjne schematy międzykulturowe. 
Yaron Matras w artykule Przekraczanie granic: przełączanie kodów jako zjawisko konwersacyjne na przykładzie rozmów Romów opisuje różne typy przełączania kodów (wtrącenia, mieszanie języków w trybie bilingwalnym). Szeroko omawia konteksty funkcjonowania przełączania kodów, jego komunikacyjne funkcje i uwarunkowania, na przykład przełączanie kodów jako efekt reakcji na bodźce $w$ obrębie sytuacji. Jest to przełączanie sytuacyjne i konwersacyjne, które wskazuje na podzielane przez społeczeństwo wartości i zasady, a także na ich akceptację bądź odrzucenie przez rozmówcę. Przełączanie kodów, jak dowodzi badacz, może pełnić również funkcje dyskursywne, polegające na sygnalizowaniu przejścia między poziomami lub warstwami dyskursu. Dzieje się tak wówczas, gdy przełączanie kodów jest metaforyczne. Kolejny podrozdział opracowania poświęca autor omówieniu strukturalnych aspektów przełączania kodów i innych modeli formalnych. Szczegółowemu opisowi zjawiska przełączania kodów towarzyszą liczne ilustracje materiałowe, a rozważania wspierane są ustaleniami teoretycznymi i objaśnieniem stosowanych metod.

Tom zamyka opracowanie Anny Wierzbickiej zatytułowane Gdy skrypty kulturowe wchodza w kolizję: Nieporozumienia komunikacyjne $w$ „wielokulturowej” Australii. Przedmiotem zainteresowania uczonej są skrypty kulturowe. Zastosowanie tej metodologii, jak pisze autorka, umożliwia identyfikację i objaśnienie różnych norm kulturowych, co ma duże znaczenie $w$ wymiarze praktycznym. Część analityczną poprzedza prezentacja teorii naturalnego metajęzyka semantycznego (NMS) wykorzystywanego w badaniach skryptów kulturowych do opisywania w prosty sposób słów kluczy danej kultury - bez uprzedzeń czy wcześniejszych założeń. Zastosowanie skryptów kulturowych ukazuje autorka, omawiając nieporozumienia występujące $w$ międzykulturowych grupach rodzinnych przedstawionych w powieści Christosa Tsiolkasa Klaps (Tsıolkas, 2012). W pragmatyce międzykulturowej dostrzega badaczka dziedzinę o wartości praktycznej: $w$ dobie globalizmu pozwala na skuteczną, bezkonfliktową komunikację $w$ wielokulturowych środowiskach. W aspekcie teoretycznym natomiast dziedzina ta przyczynia się do obalenia twierdzenia o uniwersalistycznym charakterze zachowań językowych, także grzecznościowych, objaśnia normy i wartości właściwe różnym kulturom, może zatem stanowić podstawę edukacji międzykulturowej.

Zgromadzone $w$ antologii artykuły zawierają bogate zaplecze teoretyczne i metodyczne - objaśniają najważniejsze pojęcia z zakresu lingwistyki kulturowej i międzykulturowej oraz przedstawiają propozycje metod analizy. Zaletą publikacji jest również prezentacja najnowszych ujęć teoretycznych i stanu badań, a niejednokrotnie krytyczne ich omówienia oraz propozycje autorskie wzbogacające dotychczasowe koncepcje o nowe rozwiązania teoretyczno-metodologiczne osadzone w perspektywie komunikacyjno-dyskursywnej. Pomieszczone $w$ książce opracowania mają też wymiar praktyczny czy edukacyjny - dostarczają wiedzy na temat sprawnego komunikowania się i bezkonfliktowego współistnienia $w$ wielokulturowej rzeczywistości, mogą więc stanowić inspiracje dla humanistów zainteresowanych problematyką komunikacji i kultury/międzykulturowości. 


\section{Literatura}

Geeraerts D., Grondelaers S., 1995: Looking Back at Anger: Cultural Traditions and Metaphorical Patterns. W: Taylor J.R., Maclaury R.E., red.: Language and the Cognitive Construal of the World. Berlin, s. 153-179.

KAPUŚCIŃSKı R., 2007: Inny w globalnej wiosce. W: Tegoż: Ten Inny. Kraków, s. 51-62.

Kövecses Z., 2005: Metaphor in Culture: Universality and Variation. Cambridge.

LINKE A., 2011: Signifikante Muster: Perspektiven einer kulturanalytischen Linguistik. W: WÅGHäLL Nivre E., Kaute B., Andersson B., Landén B., Stoeva-Holm D., red.: Begegnungen. Das Vill. Nordisch-Baltische Germanistentreffen in Sigtuna vom 11. bis zum 13. 6. 2009. Stockholm, s. 23-44.

Ogarkova A., Soriano C., 2014: Variation within Universals: The 'Metaphorical Profile' Approach to the Study of ANGer Concepts in English, Russian and Spanish. W: Musolff A., MacArthur F., PAGANI G., red.: Metaphor and Intercultural Communication. London, s. 93-116.

Tsıolkas Ch., 2012: Klaps. Polak J., tłum. Zakrzewo. 